\title{
GCU
}

Glasgow Caledonian

University

University for the Common Good

\section{The socio-spatial distribution of alcohol outlets in Glasgow city}

Ellaway, Anne; Macdonald, Laura; Forsyth, Alasdair; Macintyre, Sally

Published in:

Health and Place

DOI:

10.1016/j.healthplace.2009.08.007

Publication date:

2010

Document Version

Author accepted manuscript

Link to publication in ResearchOnline

Citation for published version (Harvard):

Ellaway, A, Macdonald, L, Forsyth, A \& Macintyre, S 2010, 'The socio-spatial distribution of alcohol outlets in Glasgow city', Health and Place, vol. 16, no. 1, pp. 167-172. https://doi.org/10.1016/j.healthplace.2009.08.007

\section{General rights}

Copyright and moral rights for the publications made accessible in the public portal are retained by the authors and/or other copyright owners and it is a condition of accessing publications that users recognise and abide by the legal requirements associated with these rights.

Take down policy

If you believe that this document breaches copyright please view our takedown policy at https://edshare.gcu.ac.uk/id/eprint/5179 for details of how to contact us. 
The socio-spatial distribution of alcohol outlets in Glasgow city

Anne Ellaway, Laura Macdonald, Alasdair J. M. Forsyth*, Sally Macintyre MRC Social \& Public Health Sciences Unit,

4 Lilybank Gardens, Glasgow G12 8RZ, Scotland ,UK, Glasgow

${ }^{*}$ Centre for the Study of Violence, Glasgow Caledonian University, Cowcaddens

Road, GlasgowG4 0BA, Scotland, UK 


\section{Abstract}

Aims The aim of this study was to examine the distribution of alcohol outlets by area deprivation across Glasgow, Scotland. Methods All alcohol outlets were mapped and density per 1000 residents and proximity to nearest outlet calculated across quintiles of area deprivation. Results The socio-spatial distribution of alcohol outlets varies by deprivation across Glasgow but not systematically. Some deprived areas contain the highest concentration while other in similar deprivation quintiles contain very few. Conclusions Considerations of the local context are important in examining access to alcohol but more research is also required on purchasing behaviour. 


\section{The socio-spatial distribution of alcohol outlets in Glasgow city}

Alcohol is a significant and growing problem in Scotland. Alcohol-related death rates in 2002-2004 for males and females in Scotland were around double the rate for the UK as a whole (Office for National Statistics, 2007). Cirrhosis mortality rates in Scotland are now among the highest in western Europe (Leon and McCambridge, 2006). At a local level, Glasgow City had the highest alcoholrelated death rate among both men and women in the UK in 1998-2004 (Office for National Statistics, 2007). Alcohol-related problems are estimated to cost Scotland over $£ 1$ billion every year (Scottish Executive, 2004a). It has also been suggested that excessive alcohol consumption constitues the largest public health impact on serious and repetitive violence (Coid et al., 2006).

UK sales of alcohol are rising, in 1995 an average of 9 litres of pure alcohol was sold per head of population aged 15 and over in the UK, this had risen to 11 litres per head by 2005 (British Beer and Pub Association Statistical Handbook 2007 cited in (Catto and Gibbs, 2008)). Paradoxically, population surveys conducted during that period suggested a decline in alcohol intake rather that an increase. However, a recent study reported that alcohol intake has been underestimated in UK studies, and currently it is estimated that over a third of male adults and just under a quarter of adult females in Scotland usually consume more that the recommended limit of units per week (Scottish Government, 2008). Among women in Scotland, weekly levels of consumption are highest in women in managerial and professional households and decreases with household income; whereas for Scottish men there is no consistent pattern in levels of overall weekly alcohol consumption by either socio-economic classification or household income. However, reported binge drinking among men increased as household income decreased and was lowest for men in managerial and professional occupations. Binge drinking is also more common in the most deprived areas in Scotland with $46 \%$ of men and $34 \%$ of women reporting exceeding recommended maximum levels (8 units for men, 6 units for women) in one day (Scottish Executive, 2005),

Alcohol problems occur in all social groups but there is a marked socioeconomic gradient in alcohol-related morbidity. People from the most deprived areas in Scotland are three times more likely to be admitted to hospital with an alcoholrelated diagnosis than people from the most affluent areas, while men from the most deprived areas are six times more likely to die from an alcohol-related 
condition than men from the most affluent areas (Information Services Division, 2007). Elevated rates of excessive alcohol consumption and binge drinking have been found among men in the West of Scotland area compared to the rest of Scotland, after adjustment for socio-economic factors (Gray, 2007).

Sales from supermarkets and off-licenses now account for nearly half the amount of alcohol sold in the UK (Euromonitor, 2007). Some studies at the city level, mainly North American, have suggested that the density of alcohol outlets may be higher in poorer neighbourhoods (Duncan et al., 2002, Gorman and Speer, 1997, Pollack et al., 2005, Romley et al., 2007). Studies across nations (New Zealand) showed a similar pattern (Hay et al., 2009, Pearce et al., 2008). Little is known however about the extent to which alcohol outlets are more prevalent in deprived areas in the West of Scotland. Living near alcohol outlets might encourage higher intake of alcohol or expose residents to the antisocial behaviour of others who come to buy alcohol (Forsyth et al., 2007, Scribner et al., 1999, Treno et al., 2001)

In this study we set out to examine the distribution of alcohol outlets by deprivation across the city of Glasgow, in the West of Scotland. We explore this by a variety of spatial scales (small areas and larger neighbourhoods or localities), as it has been noted that the extent to which area of residence may be important for health may depend on the spatial scale and neighbourhood boundaries used (Flowerdew et al., 2008). This work builds on a programme of research we have been conducting on features of neighbourhoods which might influence health and the ability to lead a healthy life, including access to fast food outlets, supermarkets and shops and recreation facilities (Ellaway et al., 1997, Ellaway et al., 2007, Ellaway and Macintyre, 1996, Ellaway and Macintyre, 2000, Macdonald et al., 2007, Macintyre et al., 2008, Sooman et al., 1993).

\section{Methods}

A list of alcohol outlets in Glasgow City with street addresses was obtained from Glasgow City Council in 2006 and unit postcodes were found for every outlet. The list included seven categories of outlet: public houses, off-sales (including supermarkets), private members' clubs (e.g. social clubs, sports clubs, student unions etc), entertainment (e.g. bingo halls, casinos, concert halls, nightclubs etc), restaurants, refreshment (café style premises where alcohol may be served with food) and hotels. 
Spatial scales

(i) Data zones

Look-up tables were used to link the unit postcodes to Scottish data zones, the key small-area statistical geography in Scotland (Scottish Executive, 2004b). Data zones are groups of 2001 Census output areas and the majority have populations of between 500 and 1,000 residents. They nest within local government boundaries, and where possible, they have been made to respect physical boundaries and natural communities, have a regular shape and contain households with similar social characteristics.

There are 694 data zones in the Glasgow City Council boundary, with a mean population of 832 (range $248-2243$ ) and a mean area of 25.2 hectares (Scottish Executive, 2004b). For each data zone we obtained the 2006 Scottish Index of Multiple Deprivation (SIMD) Current Income sub-domain score (Scottish Executive, 2006). The SIMD is a publicly available continuous measure of compound social and material deprivation, calculated using data such as employment, welfare benefits, health, education and housing for each data zone. We chose not to use the full index since it includes health variables and access to services, so there might have been some circularity in investigating whether it predicted access to alcohol and entertainment resources. We divided SIMD scores for Glasgow into quintiles (Q1 = least deprived, Q5 = most deprived). We calculated quintiles separately for the Glasgow city area (as opposed to using the existing Scotland wide categories) because deprived neighbourhoods are overrepresented in Glasgow.

For all alcohol outlets together, public houses, off-sales, and other alcohol outlets (clubs, entertainment, restaurants, refreshments and hotels combined) we calculated the percentage distribution of each outlet across quintiles; the mean number of outlets per 1,000 residents; and the mean network distance in metres from the centroid of each data zone to the nearest of each of the outlets. If an outlet had two types of license, e.g. public house and off-sales, they were included once in the analysis with all outlets together, but included both in the public house analysis and off-sales analysis. We chose to combine clubs, entertainment, restaurants, refreshments, and hotels because of small numbers (see table 1). 
We used population data from the General Register for Scotland's 2004 small area estimates for each data zone (Scottish Executive, 2004b) to calculate the density of each outlet per 1,000 people per quintile. (Areas without any outlets were also included). Comparison of density between quintiles was determined by ANOVA using SPSS version 14.0 .

Network analysis (i.e. finding the shortest path between two locations on a road network) was carried out for each outlet using ArcGIS version 9.1. Street maps (including point addresses) were obtained from UK Ordnance Survey (Ordnance Survey, 2006). Every outlet was geocoded by unit postcode and then matched to the street number and name. Network analysis was undertaken to find the network distance in metres from the centroid of each data zone to the nearest outlet in each category and we then calculated the mean distance to the nearest outlet within each SIMD quintile. Comparison between quintiles of mean distances to outlets was determined by ANOVA in SPSS version 14.0.

\section{(ii) Localities in Glasgow}

To provide a more meaningful exploration of the location of alcohol outlets in particular localities in Glasgow e.g. social housing projects on the periphery and inner city areas, we also used the 'ONS Intermediate geography' classification. There are 133 localities (mean population $=4000$ ) in Glasgow City, this geography was created by aggregating contiguous data zones with similar social characteristics, while considering physical boundaries (http://www.scotland.gov.uk/Topics/Government/PublicServiceReform/communityplanning). Each locality has been given a name which facilitates an understanding of the physical location and type of neighbourhood, whereas examining the distribution of outlets by datazone alone would not provide that.

For all alcohol outlets together, public houses, off-sales, and other alcohol outlets, per locality, we calculated the mean number of outlets per 1000 people.

\section{Results}

The analysis included 2221 alcohol outlets; 792 pubs, 732 off-sales, and 763 other outlets (162 clubs, 227 entertainment outlets, 234 restaurants, 49 refreshment outlets and 91 hotels). 
(table 1 about here)

\section{Distribution of alcohol outlets by quintile of deprivation}

Nearly a third of all alcohol outlets were located within quintile 2 (Q2). We have previously observed a similar concentration for other facilities and resources across Glasgow (Macintyre et al., 2008)). Although there was no significant difference between quintiles in terms of mean number of outlets overall per 1,000 residents, there was significant variation in terms of mean distance to the nearest outlet with outlets being closest within Q3 and furthest away within Q1 $(p<0.05)$. The greatest proportions of off-sales were located within quintile 2 and the most deprived quintile (Q5). There was significant variation in terms of mean distance to the nearest off sales outlet, with outlets being closest within Q3 and furthest away within the most affluent quintile $(p<0.001)$. Other types of outlets (clubs, entertainment, restaurants and hotels) and were less prevalent and more distant in the more deprived quintiles (Q4 \& Q5)

\section{Distribution of alcohol outlets by localities in Glasgow}

Within Glasgow, the City Centre West and East areas have the greatest number of alcohol outlets per 1,000 population (data available from authors). Laurieston \& Tradeston (i.e. the old Gorbals) along with Parkhead West \& Barrowfield and Calton, Gallowgate \& Bridgeton (which together comprise the old East End), which are very deprived areas in the east end of the city, have the second greatest number of off-sales.

Glasgow's four main peripheral schemes (post-war slum clearance social housing estates, analgous to the American term 'project') Drumchapel/Drumry, Castlemilk/Glenwood, Pollok/Nitshill and Easterhouse/Barlanark did not have a high density of alcohol outlets of any kind. Outside the main city centre or entertainment areas, the east end of the city appears to be well provided with opportunities to buy alcohol. Figures 1-3 show the physical location of outlets by type across the city, public houses are more often located in the city centre and along arterial roads, whereas off sales are distributed more evenly throughout the city. 
Our study has shown that the socio-spatial distribution of alcohol outlets across Glasgow does vary by deprivation but not systematically. Some deprived areas contain the highest concentration while other with a similar deprivation score contain very few. It is therefore important to examine the local context of deprivation. The monolithic social housing schemes on the periphery of Glasgow are not particularly well served with opportunities to buy alcohol in their local area. This may be due to historical influences, given that these schemes were built with few amenities (Brennan, 1959, Forbes and Robertson, 1981, Pacione, 1979) and there were deliberate policies and practices to discourage alcohol use by working class residents in these areas (Maver, 2000). As early as 1954 local newspapers were highlighting the inconsistencies in social housing schemes where, as a legacy of the temperance movement, there was a vigorous enforcement of prohibition on Glasgow Corporation-owned property (Maver, 2000). A post war housing scheme like Pollok which had a population of 40,000 had no pubs. It has been suggested that this resulted in a proliferation of 'shebeens' (unlicensed drinking dens usually in a domestic dwelling) in Glasgow's housing schemes and substantiated the argument that restrictions encouraged illegal drinking and perpetuated alcohol abuse (Maver, 2000). Anecdotes abound about the continued existence of 'shebeens' in these areas, although evidence is scant.

Our results suggest a different pattern of compared to studies conducted elsewhere, for example studies in North America or of New Zealand show a higher concentration of alcohol outlets in deprived areas, whereas in Glasgow there is a more mixed picture.

The question remains however whether local opportunities to purchase alcohol are associated with alcohol consumption and health outcomes. Some areas within the east end of Glasgow (e.g. Calton and Bridgeton) are well provided with alcohol outlets (one outlet for every 85 people) and alcohol related hospital admissions and deaths are indeed higher than the Scottish average (226\% above for hospital admissions and $450 \%$ above for deaths) in these areas (Whyte, 2008). However, other areas of the city which have fewer alcohol outlets but are similarly deprived (in the bottom quintile) also have alcohol related hospital admissions and deaths which are considerably higher than the Scottish average (although not as high as the east end of Glasgow). Our next step will therefore be to examine the 
associations between proximity to alcohol outlets and alcohol consumption (using data from local studies).

In response to concerns over alcohol consumption and related social and health outcomes, policy attention in Scotland has been increasingly focussed upon restricting access to alcohol. Our findings indicate that the patterning of alcohol outlets does vary by area deprivation across Glasgow. However, a limitation of our study is that we do not know where people actually purchase alcohol and to what extent local demand drives supply or vice versa. In addition, people may also travel further afield to take advantage of in-store promotions on alcohol. Further research is required on alcohol purchasing behaviour across social groups and locations. 
Table 1 Per Scottish Index of Multiple Deprivation (SIMD) quintile: number of alcohol licences; mean number per 1,000 residents (range); mean distance to nearest (range).

\begin{tabular}{|c|c|c|c|c|}
\hline & & Number & $\begin{array}{l}\text { Mean N per 1,000 } \\
\text { residents (range) }\end{array}$ & $\begin{array}{c}\text { Mean distance (metres) to } \\
\text { nearest resource (range) }\end{array}$ \\
\hline \multicolumn{5}{|c|}{ All alcohol licenses } \\
\hline \multirow[t]{7}{*}{ SIMD Quintile } & 1 Most Affluent & 317 & $2.54(0-43)$ & $407(10-1581)$ \\
\hline & 2 & 718 & $5.94(0-271)$ & $319(0.8-3098)$ \\
\hline & 3 Middling & 463 & $3.79(0-70)$ & $306(0.3-1568)$ \\
\hline & & 288 & $2.50(0-13)$ & $366(0.5-2273)$ \\
\hline & 5 Most Deprived & 435 & $3.87(0-105)$ & $372(0-1441)$ \\
\hline & Total & 2221 & $3.73(0-271)$ & $354(0-30.98)$ \\
\hline & & & $\begin{array}{l}F=1.62 p=0.168 \\
F=2.14 p=0.094\end{array}$ & $\begin{array}{l}F=2.69 p=0.030 \\
F=3.56 p=0.014\end{array}$ \\
\hline \multirow{9}{*}{$\begin{array}{l}\text { Public Houses } \\
\text { SIMD Quintile }\end{array}$} & & & & \\
\hline & 1 Most Affluent & 103 & $0.80(0-22)$ & $696(10-2674)$ \\
\hline & & 272 & $2.22(0-133)$ & $556(14-3098)$ \\
\hline & 3 Middling & 168 & $1.34(0-30)$ & $590(2-2059)$ \\
\hline & & 103 & $0.88(0-10)$ & $605(14-2273)$ \\
\hline & 5 Most Deprived & 146 & $1.30(0-47)$ & $656(25-1904)$ \\
\hline & Total & 792 & $1.31(0-133)$ & $621(2-3098)$ \\
\hline & & & $F=1.14 p=0.337$ & $F=2.00 p=0.093$ \\
\hline & & & $F=0.05 p=0.828$ & $\mathrm{~F}=0.07 \mathrm{p}=0.794$ \\
\hline \multirow{8}{*}{$\begin{array}{l}\text { Off-sales }^{1} \\
\text { SIMD Quintile }\end{array}$} & & & & \\
\hline & 1 Most Affluent & 88 & $0.71(0-10)$ & 545 (26-2779) \\
\hline & & 180 & $1.53(0-31)$ & $432(42-4403)$ \\
\hline & 3 Middling & 156 & $1.34(0-12)$ & $401(6-1606)$ \\
\hline & & 128 & $1.14(0-6)$ & $445(0.5-2273)$ \\
\hline & 5 Most Deprived & 180 & $1.72(0-10)$ & $443(0-1662)$ \\
\hline & Total & 732 & $1.29(0-31)$ & $453(0-4403)$ \\
\hline & & & $\begin{array}{l}F=4.24 p=0.002 \\
F=7.42 p=0.007\end{array}$ & $\begin{array}{l}F=3.01 p=0.018 \\
F=3.71 p=0.055\end{array}$ \\
\hline \multirow{8}{*}{$\begin{array}{l}\text { Others }^{2} \\
\text { SIMD Quintile }\end{array}$} & & & & \\
\hline & 1 Most Affluent & 134 & $1.10(0-20)$ & $585(25-2685)$ \\
\hline & & 297 & $2.43(0-127)$ & $529(0.8-3161)$ \\
\hline & 3 Middling & 155 & $1.23(0-38)$ & $604(0.3-2113)$ \\
\hline & & 60 & $0.51(0-7)$ & $724(68-2591)$ \\
\hline & 5 Most Deprived & 117 & $0.95(0-50)$ & $821(48-2012)$ \\
\hline & Total & 763 & $1.25(0-127)$ & $652(0.3-3161)$ \\
\hline & & & $\begin{array}{l}F=1.93 p=0.104 \\
F=1.86 p=0.173\end{array}$ & $\begin{aligned} F & =8.21 p=0.000 \\
F=26.24 p & =0.000\end{aligned}$ \\
\hline
\end{tabular}

${ }^{1}$ includes outlets only selling alcohol e.g. Haddows and also supermarkets and other shops selling alcohol.

${ }^{2}$ includes clubs (e.g. social clubs, sports clubs, student unions etc), entertainment (e.g. nightclubs, bingo halls, casinos, concert halls etc), restaurant, refreshment and hotels. 
References

BRENNAN, T. (1959) Reshaping a City, Glasgow, The House of Grant.

CATTO, S. \& GIBBS, D. (2008) How much are people in Scotland really drinking? A review of data from Scotland's routine national surveys. Edinburgh, Health Scotland.

COID, J., ROBERTS, A., MORAN, P., BEBBINGTON, P., BRUGHA, T., JENKINS, R., FARRELL, M., LEWIS, G. \& SINGLETON, N. (2006) Violence and psychiatric morbidity in the national household population of Britain: Prevalence and public health implications. British Journal of Psychiatry, 189, 12-19.

DUNCAN, S. C., DUNCAN, T. E. \& STRYCKER, L. A. (2002) A multilevel analysis of neighborhood context and youth alcohol and drug problems. Prev Sci, 3, 125-33.

ELLAWAY, A., ANDERSON, A. \& MACINTYRE, S. (1997) Does area of residence affect body size and shape? International Journal of Obesity, 21, 304-308.

ELLAWAY, A., KIRK, A., MACINTYRE, S. \& MUTRIE, N. (2007) Nowhere to play? The relationship between the location of outdoor play areas and deprivation in Glasgow. Health \& Place, 13, 557-561.

ELLAWAY, A. \& MACINTYRE, S. (1996) Does where you live predict health related behaviours? A case study in Glasgow. Health Bulletin, November, Vol. 54, 443446.

ELLAWAY, A. \& MACINTYRE, S. (2000) Shopping for food in socially contrasting neighbourhoods. British Food Journal, 102, 52-59.

EUROMONITOR (2007) Alcoholic Drinks in the United Kingdom.

FLOWERDEW, R., MANLEY, D. \& SABEL, C. (2008) Neighbourhood effectss on health: Does it matter where you draw the boundaries. Social Science \& Medicine, 66, 1241-1255.

FORBES, J. \& ROBERTSON, I. (1981) Patterns of Residential Movements in Greater Glasgow. Scottish Geographical Magazine, 97, 85-91.

FORSYTH, A., DAVIDSON, N. \& LENNOX, J. L. (2007) An Investigation into the environmental impact of off-licensed premises on residential neighbourhoods. . Alcohol Education Research Council.

GORMAN, D. M. \& SPEER, P. W. (1997) The concentration of liquor outlets in an economically disadvantaged city in the northeastern United States. Substance Use \& Misuse, 32, 2033-2046.

GRAY, L. (2007) Comparisons of health-related behaviours and health measures between Glasgow and the rest of Scotland. Glasgow, Glasgow Centre for Population Health.

HAY, G., WHIGHAM, P., KYPRI, K. \& LANGLEY, J. (2009) Neighbourhood deprivation and access to alcohol outlets: A national study. Health \& Place.

INFORMATION SERVICES DIVISION (2007) Alcohol Statistics Scotland. Edinburgh.

LEON, D. \& MCCAMBRIDGE, J. (2006) Liver cirrhosis mortality rates in Britain from 1950 to 2002: an analysis of routine data. The Lancet, 367, 52-56.

MACDONALD, L., CUMMINS, S. \& MACINTYRE, S. (2007) Neighbourhood fast food environment and area deprivation- substitution or concentration? Appetite, 49, 251254.

MACINTYRE, S., MACDONALD, L. \& ELLAWAY, A. (2008) Do poorer people have poorer access to local resources and facilities? The distribution of local resources by area deprivation in Glasgow, Scotland. Social Science \& Medicine 67, 900-14.

MAVER, I. (2000) Glasgow, Edinburgh, Edinburgh University Press.

OFFICE FOR NATIONAL STATISTICS (2007) Health Statistics Quarterly. London.

ORDNANCE SURVEY (2006) OS MasterMap (CD-ROM). Southampton, UK, Ordnance Survey.

PACIONE, M. (1979) Housing Polices in Glasgow since 1880. The Geographical Review, $69,395-412$. 
PEARCE, J., DAY, P. \& WITTEN, K. (2008) Neighbourhood provision of food and alcohol retaining and social deprivation in urban New Zealand. Urban Policy and Research, 26, 213-227.

POLLACK, C. E., CUBBIN, C., AHN, D. \& WINKLEBY, M. (2005) Neighbourhood deprivation and alcohol consumption: does the availability of alcohol play a role? International Journal of Epidemiology, 34, 772-780.

ROMLEY, J. A., COHEN, D., RINGEL, J. \& STURM, R. (2007) Alcohol and environmental justice: The density of liquor stores and bars in urban neighborhoods in the United States. Journal of Studies on Alcohol and Drugs, 68, 48-55.

SCOTTISH EXECUTIVE (2004a) Cost to Society of Alcohol Misuse: update. Edinburgh

SCOTTISH EXECUTIVE (2004b) Scottish Executive Scottish Neighbourhood Statistics Data Zones Scottish Executive.

SCOTTISH EXECUTIVE (2005) The Scottish Health Survey 2003. Edinburgh.

SCOTTISH EXECUTIVE (2006) Scottish Index of Multiple Deprivation 2006. Edinburgh, Scottish Executive.

SCOTTISH GOVERNMENT (2008) Revised alcohol consumption estimates from the 2003 Scottish Health Survey. Edinburgh.

SCRIBNER, R., COHEN, D., KAPLAN, S. \& ALLEN, S. H. (1999) Alcohol availability and homicide in New Orleans: Conceptual considerations for small area analysis of the effect of alcohol outlet density. Journal of Studies on Alcohol, 60, 310-316.

SOOMAN, A., MACINTYRE, S. \& ANDERSON, A. (1993) Scotland's Health - A more difficult challenge for some? The price and availability of healthy foods in socially contrasting localities in the West of Scotland. Health Bulletin, 51(5), 276-284.

TRENO, A. J., GRUENEWALD, P. J. \& JOHNSON, F. W. (2001) Alcohol availability and injury: The role of local outlet densities. Alcoholism-Clinical and Experimental Research, 25, 1467-1471.

WHYTE, B. (2008) A Community Health and Wellbeing Profile for East Glasgow. Glasgow, Glasgow Centre for Population Health. 